Article

\title{
Satellite-Observed Urbanization Characters in Shanghai, China: Aerosols, Urban Heat Island Effect, and Land-Atmosphere Interactions
}

\author{
Menglin S. Jin ${ }^{1}{ }^{*}$, Wittaya Kessomkiat ${ }^{1}$ and Gary Pereira ${ }^{2}$ \\ 1 Department of Meteorology and Climate Science, San José State University, San Jose, CA 95192, \\ USA; E-Mail: wittaya@met.sjsu.edu \\ 2 Department of Geography, San José State University, San Jose, CA 95192, USA; \\ E-Mail: Gary.Pereira@sjsu.edu \\ * Author to whom correspondence should be addressed; E-Mail: jin@ met.sjsu.edu.
}

Received: 16 November 2010; in revised form: 20 December 2010 / Accepted: 4 January 2011 / Published: 7 January 2011

\begin{abstract}
Urbanization reflects how human-activities affect natural climate system. Accurately assessing the urban system by comparing it with the nearby rural regions helps to identify the impacts of urbanization. This work uses the recent satellite observed aerosol, skin temperature, land cover, albedo, cloud fraction and water vapor measurements to reveal how the city of Shanghai, one of the biggest, dense urban areas in East Asia, affects land surface and atmosphere conditions. In addition, the National Aeronautics and Space Administration (NASA) ground observations from AErosol RObotic NETwork (AERONET) is also used to reveal diurnal, seasonal, and interannual variations of the heavy aerosol load over Shanghai region. Furthermore, Shanghai reduces surface albedo, total column water vapor, cloud fraction and increases land skin temperature than rural region. These observations prove that Shanghai significantly modifies local and regional land surface physical properties as well as physical processes, which lead to the urban heat island effect (UHI).
\end{abstract}

Keywords: urban system; surface heat island effect; urban aerosols; remote sensing 


\section{Introduction}

Numerous studies suggest that urbanization changes in surface energy budget [1-3]. The land surface energy budget can be described as [4]:

$$
(1-\alpha) \mathrm{S}_{\mathrm{d}}+\mathrm{LW}_{\mathrm{d}}-\varepsilon \sigma \mathrm{T}_{\text {skin }}{ }^{4}-\mathrm{SH}-\mathrm{LE}-\mathrm{G}=0
$$

where $\alpha$ is surface albedo, $\mathrm{S}_{\mathrm{d}}$ is downward surface insulation. $\mathrm{LW}_{\mathrm{d}}$ is downward longwave radiation. $\varepsilon$ is surface emissivity. $\sigma$ is the Steven Boltzmann constant. $\mathrm{T}_{\text {skin }}$ is the land surface skin temperature. $\mathrm{SH}, \mathrm{LE}$ are the sensible and latent heat fluxes. $\mathrm{G}$ is the ground heat flux. Urbanization, by changing atmosphere as well as land surface, modifies all the terms in Equation (1): First, urban has high aerosols load in the urban atmosphere, which reduces the surface insulation. Previous research [5] reported that the reduction of surface insulation, so-called aerosol direct effect [6], could be up to $20-40 \mathrm{Wm}^{-2}$ for a normally polluted sky for New York City and may be about $100 \mathrm{Wm}^{-2}$ for the dense polluted city (Beijing) in summer. In addition, certain types of aerosols ( $c f$. soot) absorb and emit longwave radiation and thus change $\mathrm{LW}_{\mathrm{d}}$ in Equation (1). Furthermore, the clouds microphysical properties (cloud droplet size, cloud top albedo, etc) are changed due to aerosol's indirect effect [7], which may further affect cloud and even rainfall formation. Therefore, cloud cover changes the $L_{\mathrm{d}}$ term in Equation (1). Second, besides the atmosphere conditions, land surface parameters are also modified by urbanization. Jin et al. [8] showed that urbanization changes surface albedo, surface emissivity as well as skin temperature. As a result, SH, LE and G, which are function of land surface temperature, are expected to be changed by urbanization. All the above mentioned changes are considered as the urban impact on climate system.

Urban impact varies with the location, size, population density, and traffic pattern of a city [2]. Therefore, assessing urban physical properties from the most advanced observations is the first step to understand urban impacts. This paper focuses on Shanghai, China, which is the biggest city in East Asia, with over 20 million people. Shanghai is located on China's southeastern coast at the Yangtze River delta and covers areas over $7,000 \mathrm{~km}^{2}$. With the rapid economic growth in China, Shanghai has rapidly developed over the past decades and the urban area of Shanghai has now expanded more than $5,000 \mathrm{~km}^{2}$. Figure 1 is the Landsat measurements revealing the dramatic spatial growth of Shanghai from 1989 to 2005. As a result of that, air pollution becomes one of important environmental issues in Shanghai. In addition, Shanghai has subtropical climate and therefore has four seasons: winter, spring, summer, and fall, with cold but dry winters and warm but humid summers. Extreme heat in warm summer is observed due to urban heat island effect (UHI).

By comparing the differences between the Shanghai city and the nearby rural areas, this paper sheds light on the quantitative changes an urban system induced to this area. This paper analyzes land albedo change, atmosphere aerosol and water vapor changes over Shanghai and rural regions. The National Aeronautics and Space Administration (NASA) Moderate Resolution Imaging Spectroradiometer (MODIS) remote sensing observations, together with the AErosol RObotic NETwork (AERONET) ground observations are used to identify the spatial and temporal features of aerosol load, albedo, skin temperature, and land cover in Shanghai and nearby rural regions. 
Figure 1. The growth of urban regions over Shanghai, China. (a) is based on Landsat TM for year 1989, and (b) is for Year 2008 from Landsat ETM+. Rural is generally blue, water is black, urban is gold. Data is using Near-to-mid-infrared spectrum.

(a)

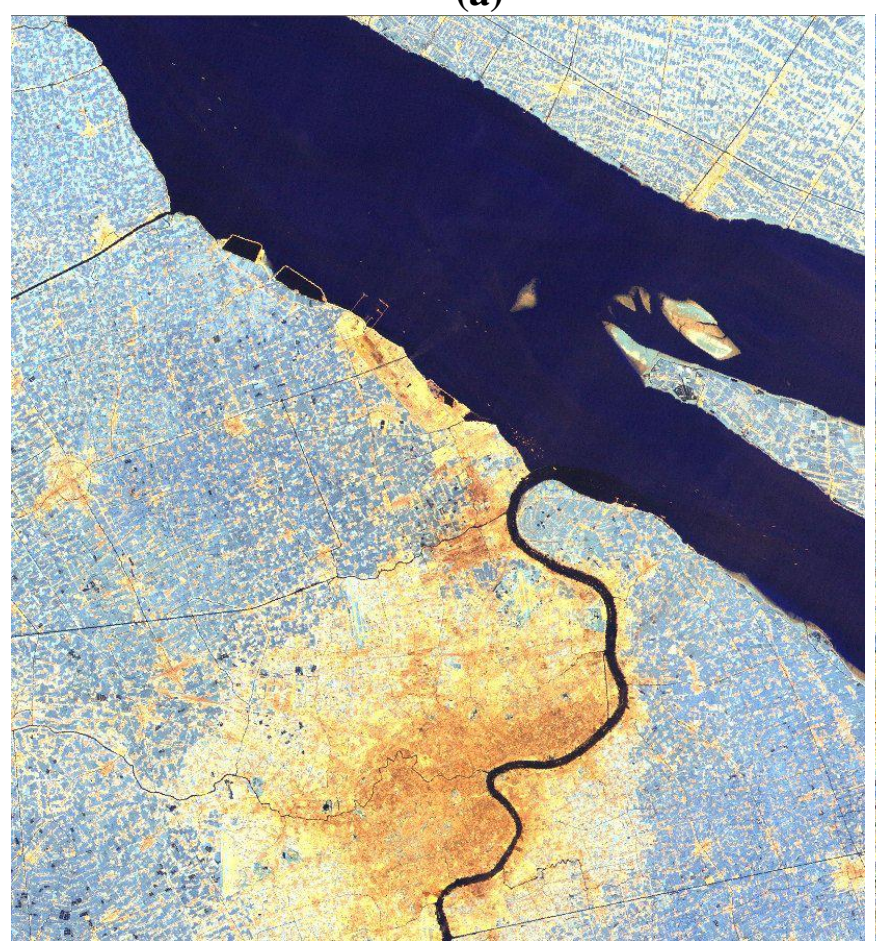

(b)

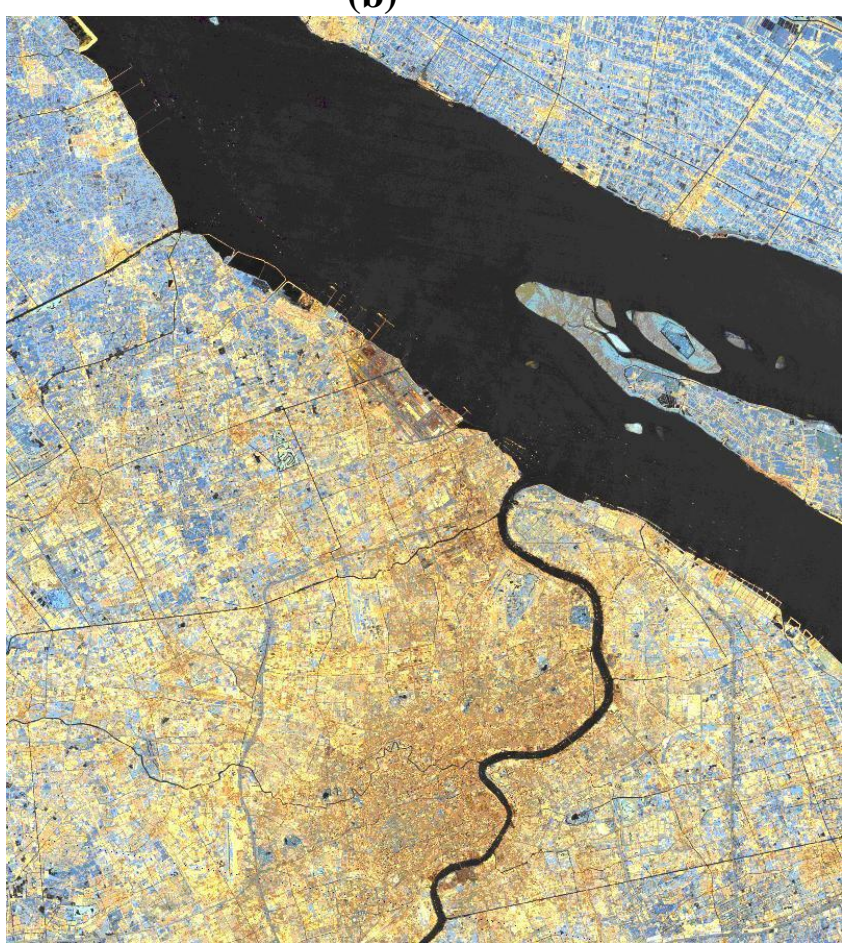

Besides aerosol, urban heat island effect (UHI) is the most significant land surface feature in urban system. UHI means that the surface temperature over urban is higher than that over rural regions [1]. Using satellite observed land skin temperature, Jin et al. [8] reported that urban surface temperature is higher than the surrounding rural regions for Beijing area. In this paper, UHI from satellite-retrieved skin temperature $\left(\mathrm{T}_{\text {skin }}\right)$ data is assessed for Shanghai and its rural regions. Again, a clear UHI signal is observed for Shanghai.

Section 2 describes the data sets and variables analyzed. Section 3 presents the new results, followed by a discussion on the urban land and atmosphere interactions in terms of the change in the land surface energy budget (Section 4).

\section{Data}

Monthly observations of skin temperature $\left(\mathrm{T}_{\text {skin }}\right)$, albedo, and land cover data measured by MODIS Terra [9-12] from March 2000 to December 2008 are used to analyze the climatology of skin temperature and how it relates to surface properties. Details of MODIS skin temperature collection 5 process and validation can be found at Wan [9], or the user's guide at (http://www.icess.ucsb.edu/ modis/LstUsrGuide/MODIS_LST_products_Users_guide_C5.pdf). The MODIS data (Collection 5) is at $0.05^{\circ}$ latitude/longitude grid, or so-called Climate Model Grid (CMG) resolution in MODIS. $\mathrm{T}_{\text {skin }}$ data is only retrieved on clear days. The daytime and nighttime $\mathrm{T}_{\text {skin }}$ values in MOD11C3 are averaged from the daytime and nighttime LST values in the daily $\mathrm{T}_{\text {skin }}$ product (MOD11C1) in clear-days only. The daytime $\mathrm{T}_{\text {skin }}$ in MOD11C1 is around 10:30 AM local solar time and the nighttime $\mathrm{T}_{\text {skin }}$ is around 
10:30 PM local solar time. The observation time may differ by 90 minutes in low latitude regions or up to several hours in high latitude regions. Local solar time is equal to Coordinated Universal Time (UTC) + longitude (in degrees)/15.

Aerosol optical thickness (AOT) observations from MODIS Collection 5 [6,13] are also used in this paper to identify the aerosol load in one atmospheric column. In addition, water vapor and cloud observations from MODIS [14,15] are also used to examine the connections between surface temperature and atmospheric conditions. MODIS atmosphere data are at $1^{\circ}$ by $1^{\circ}$ resolution. Aerosol measurements are only available for clear-day conditions and are sampled into monthly data.

AERONET data from the Taihu Site $\left(31^{\circ} 25^{\prime} 15^{\prime \prime} \mathrm{N}, 120^{\circ} 12^{\prime} 54^{\prime \prime} \mathrm{E}\right)$ are analyzed to show the diurnal, seasonal, and interannual variations of aerosol optical thickness (AOT) in this region [16]. Hourly data of AOT with level 2.0 quality assured [17] available from 2005 to 2008 to show the diurnal, seasonal, and interannual patterns of AOT. Taihu site is close to Shanghai. Since near-surface wind is from Shanghai to Taihu (see Figure 2 below), AOT of Taihu is largely transported from Shanghai. Because AERONET does not have site over Shanghai, using nearby Taihu-site observed AOT to represent Shanghai is valid.

Figure 2. Shanghai Land Cover. The land cover is defined by MODIS as (1). Evergreen Needleleaf Forest, (2). Evergreen Broadleaf Forest, (3). Deciduous Needleleaf Forest, (4). Deciduous Broadleaf Forest, (5). Mixed Forest, (6). Closed Shrubland, (7). Open Shrubland, (8). Woody Savannas, (9). Savannas, (10). Grassland, (11). Permanent Wetland, (12). Cropland, (13). Urbanand Built-up, (14). Cropland/Natural Vegetation Mosaic, (15). Snow and Ice, (16). Barren or Sparsely Vegetated. In addition, 0 is water. Both studies Shanghai region and the selected region are outlined by rectangular boxes.

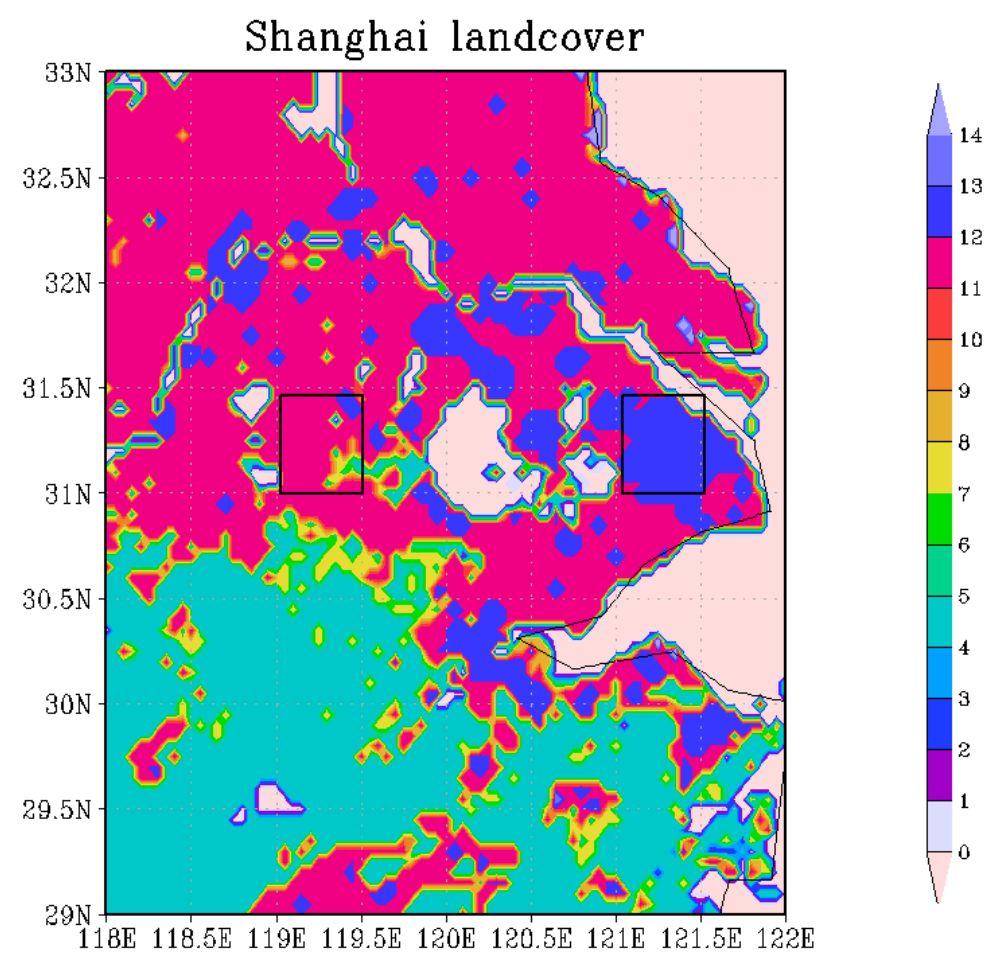


Monthly reanalysis outputs from the European Centre for Medium-Range Weather Forecasts (ECMWF) reanalysis (ERA-40) are analyzed to reveal the regional wind circulation at $925 \mathrm{mb}$. ERA-40 is a new reanalysis project conducted at ECMWF to cover the period from mid-1957 to 2001 including the earlier ECMWF reanalysis ERA-15, 1979-1993. The reanalysis data this study uses is monthly surface wind at $925 \mathrm{mb} 2.5^{\circ}$ by $2.5^{\circ}$. The data are freely available at http://www.ecmwf.int/research/era/do/get/era-40.

\section{Results}

\section{Land Cover}

Land cover can be used to distinguish urban regions and rural regions. Figure 2 clearly shows that Shanghai is a big urban region (the blue color, $\mathrm{LC}=12$ ) and the selected rural region, which is outlined in a black rectangle box, is cropland $(\mathrm{LC}=11)$. The selected rural region is $2^{\circ}$ west of Shanghai but at the same latitude. Selecting rural region at the same latitude is to ensure that both urban and rural has the same solar radiation input for clear days. In addition, although the urban region of Shanghai is irregular, a boxed Shanghai region is analyzed to keep the rural and urban counterparts have the same size for comparison. Furthermore, the big water body (LC $=0)$ between Shanghai and the selected rural region is Taihu, where AERONET has a ground-based aerosol site.

Urban system, as a sub-component of the Earth climate system, is largely determined by the atmosphere circulation. Therefore, to obtain a broad view of atmosphere circulation of these regions, Figure 3 shows the ERA-40 surface wind at $925 \mathrm{mb}$ in July 2002. Overall, Shanghai and its surrounding areas are influenced by warm air from the southwest wind and cold air from the north wind. More importantly, the wind at near surface is from Shanghai to Taihu, and therefore, the aerosols over Shanghai are transported into Taihu. This is the base that Taihu AERONET observation is used to reveal the possible temporal features of Shanghai urban aerosols (see figures latter).

Figure 3. ECMWF analysis monthly wind at $925 \mathrm{mb}$ for July 2002.

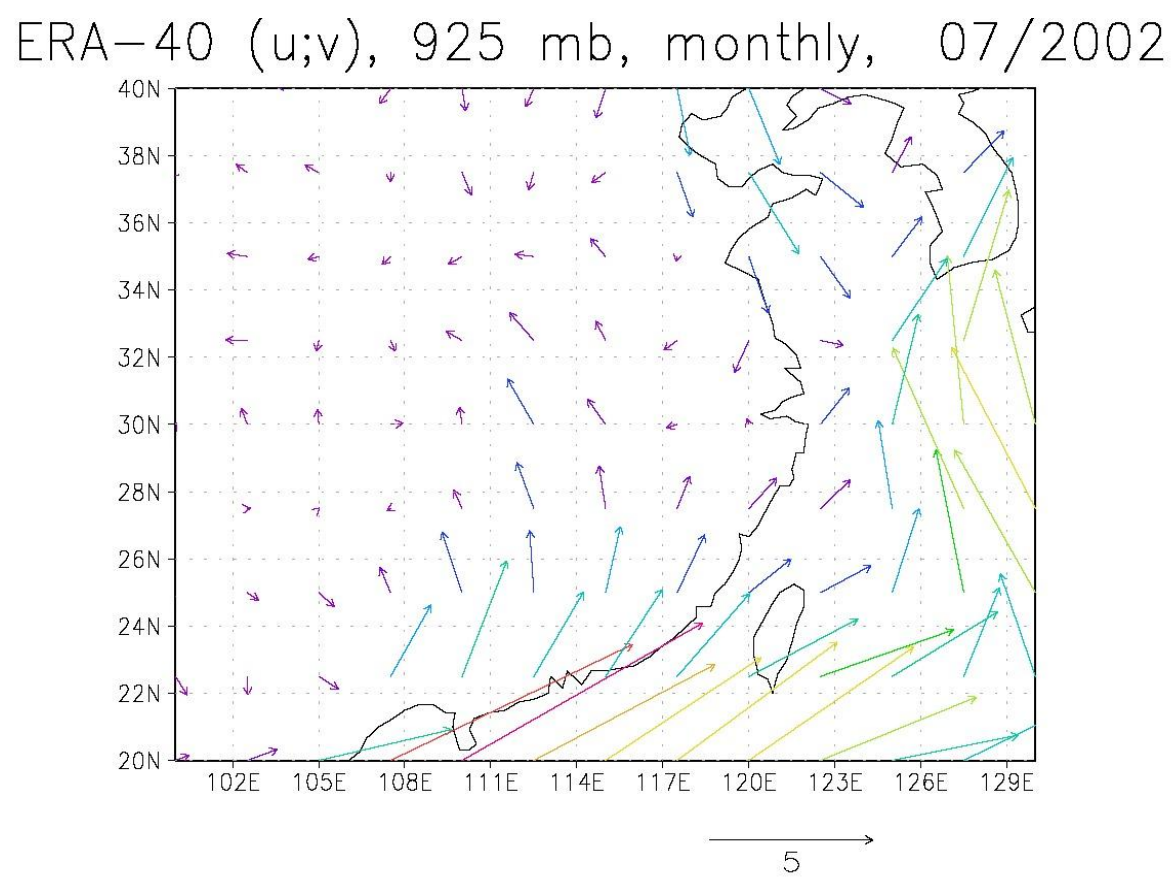




\section{Skin Temperature}

$\mathrm{T}_{\text {skin }}$, obtained from MODIS Terra at 10:30 AM, over Shanghai and rural areas for the Julys of 2001 and 2004 (Figure 4, other Julys in 2001-2008 are also analyzed but not shown here) shows that Shanghai is much warmer than the rural regions in Julys. In addition, $\mathrm{T}_{\text {skin }}$ varies across the city of Shanghai, determined by specific local underlying surface structure, vegetation coverage, and the geography conditions. For example, even for an urban region, $\mathrm{T}_{\text {skin }}$ differs from $300 \mathrm{~K}$ to $312 \mathrm{~K}$. The warmest part of Shanghai is the dense building regions, with $\mathrm{T}_{\text {skin }}$ upto $310 \mathrm{~K}$. This is due to the urban high heterogeneity. For comparison, the selected rural regions have overall $\mathrm{T}_{\text {skin }}$ from 304 to $308 \mathrm{~K}$, which is much cooler than Shanghai regions and has much less $T_{\text {skin }}$ variations across the study area. Similar warm signal is evident for July 2004 (Figure 4(b)) as well as for the rest Julys during 2000-2008. Furthermore, inter-annual variations of UHI are also evidently shown in Figure 4, by comparing July 2001 (Figure 4(a)) with July 2004 (Figure 4(b)).

Figure 4. Monthly mean $\mathrm{T}_{\text {skin }}$ in July for (a) 2001 and (b) 2004 with Shanghai (right box) and rural (left box). The $\mathrm{T}_{\text {skin }}$ data is obtained from Terra MODIS at 10:30 AM.

(a)

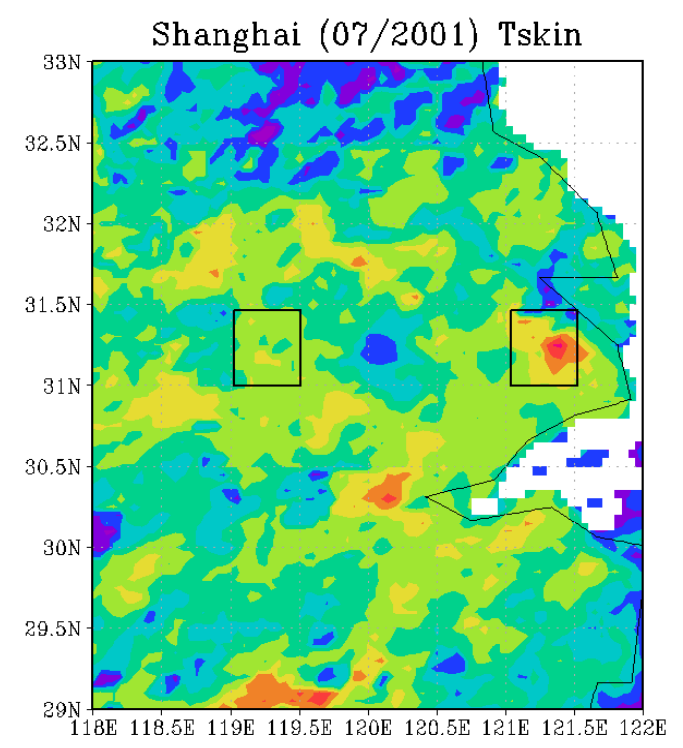

(b)

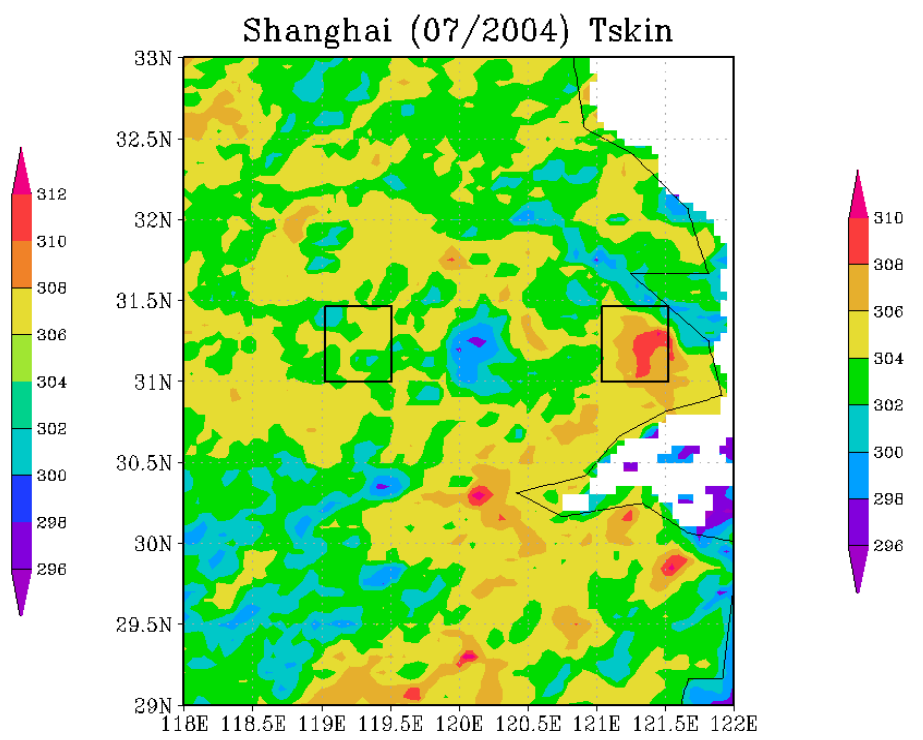

Monthly, area-averaged $\mathrm{T}_{\text {skin }}$ (Figure 5(a-f)) shows that, in general, Shanghai is warmer than the rural region except for Junes in 2001 and 2003, January in 2002, January and November in 2004, and February in 2005. Specifically, Shanghai is hotter than and rural region by about $5^{\circ} \mathrm{K}$ in July, 2005. Nevertheless, rainfall and wind may be the primary reasons for the lower Shanghai $\mathrm{T}_{\text {skin }}$ for the few months when lower $\mathrm{T}_{\text {skin }}$ were observed for Shanghai. 
Figure 5. Monthly averaged $T_{\text {skin }}$ for Shanghai and rural areas in (a) 2001, (b) 2002, (c) 2003, (d) 2004, (e) 2005, and (f) 2006, where red solid line represents Shanghai and blue solid line represents rural.
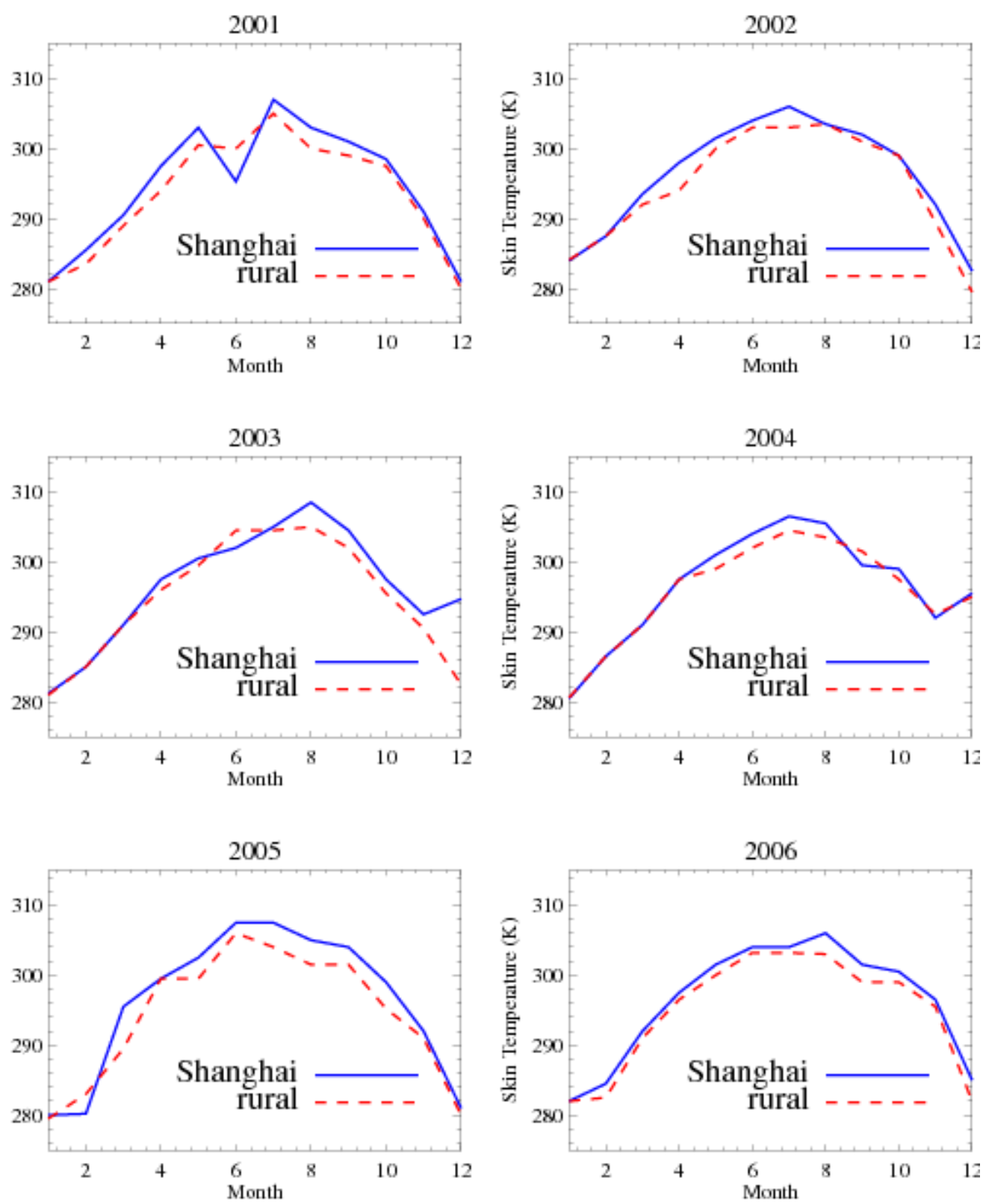

\section{Albedo}

Albedo determines the amount of absorbed surface insolation (Equation 1). Shanghai has lower surface albedo than the rural regions for January, April, and July 2004 (Figure 6(a-c)). This is consistent with previous study that urban regions reduce the abledo by replacing the vegetation-covered natural surfaces with human constructions [5]. For comparison, albedo in December, 2004 (Figure 6(d)) is slightly higher in Shanghai than in the rural regions. Further analyses imply that the high winter albedo in Shanghai may be a result of contamination of clouds and snow surface. Urban albedo varies significantly during one year, determined by soil moisture, vegetation 
condition, building canyon effect, etc. More importantly, even for Shanghai itself, spatial variations on albedo are evident.

Figure 6. Albedo in 2004 for (a) January, (b) April, (c) July, and (d) December with Shanghai (right box) and rural (left box).

(a)

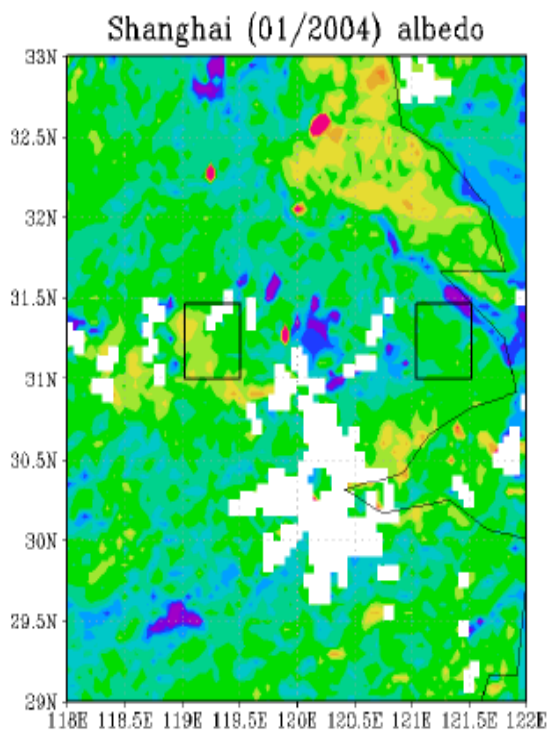

(c)

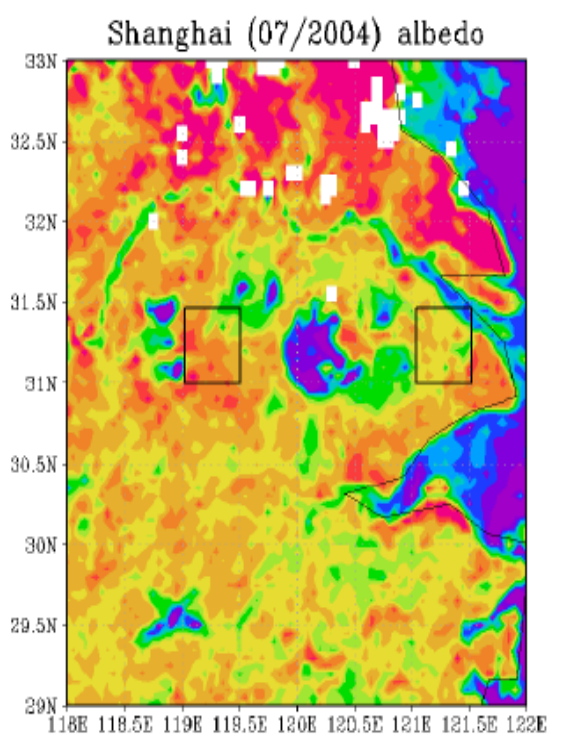

(b)

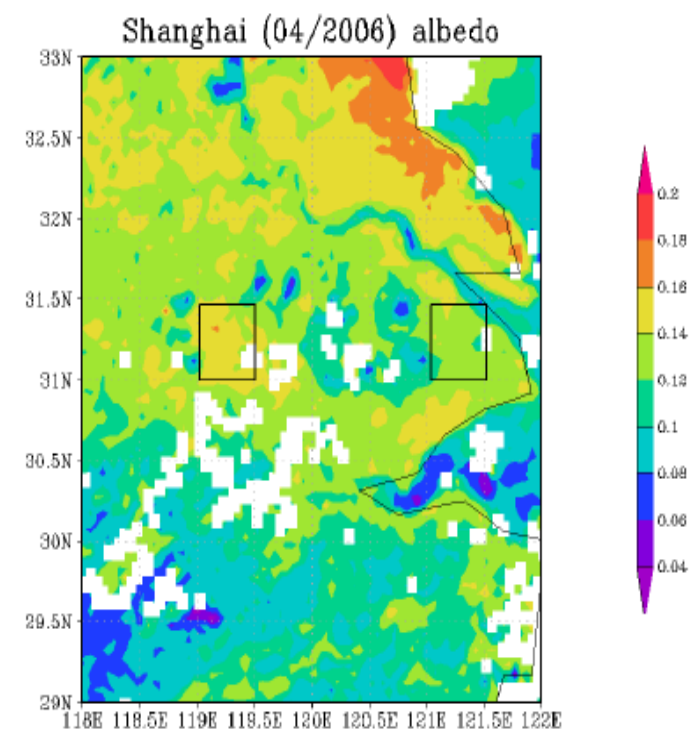

(d)

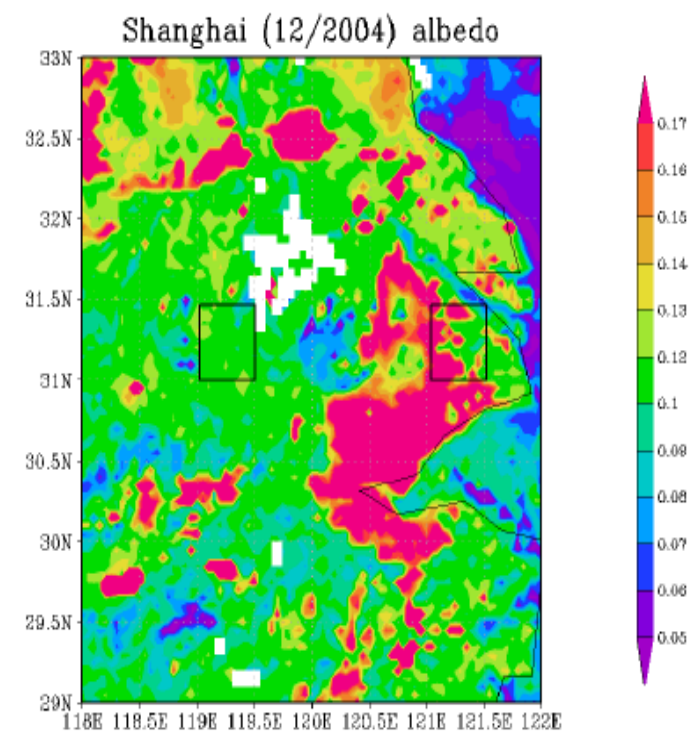

Moreover, monthly, area-averaged albedo shows that in most of the months during 2004 (Figure 7), Shanghai's albedo is lower than that of the rural region. The big reduction occurs in January, February and April where Shanghai albedo is $1-3 \%$ lower than the rural area. Nevertheless, both Shanghai and the rural region do not have evident seasonal variation except for that in December Shanghai has higher albedo as indicated in Figure 6(d), when the largest difference between Shanghai and rural albedo is found in December with the magnitude of 0.05. Again, this high albedo in Shanghai may be questionable due to the cloud contamination. Furthermore, from Spring to early Fall 
(April-September) the albedo is relatively stable partly due to the growing of surface vegetation. Note that MODIS albedo is wavelength-integrated albedo, namely, so-called broadband albedo.

Figure 7. Monthly averaged albedo in 2004, where the solid line represents Shanghai and the dashed line represents rural.

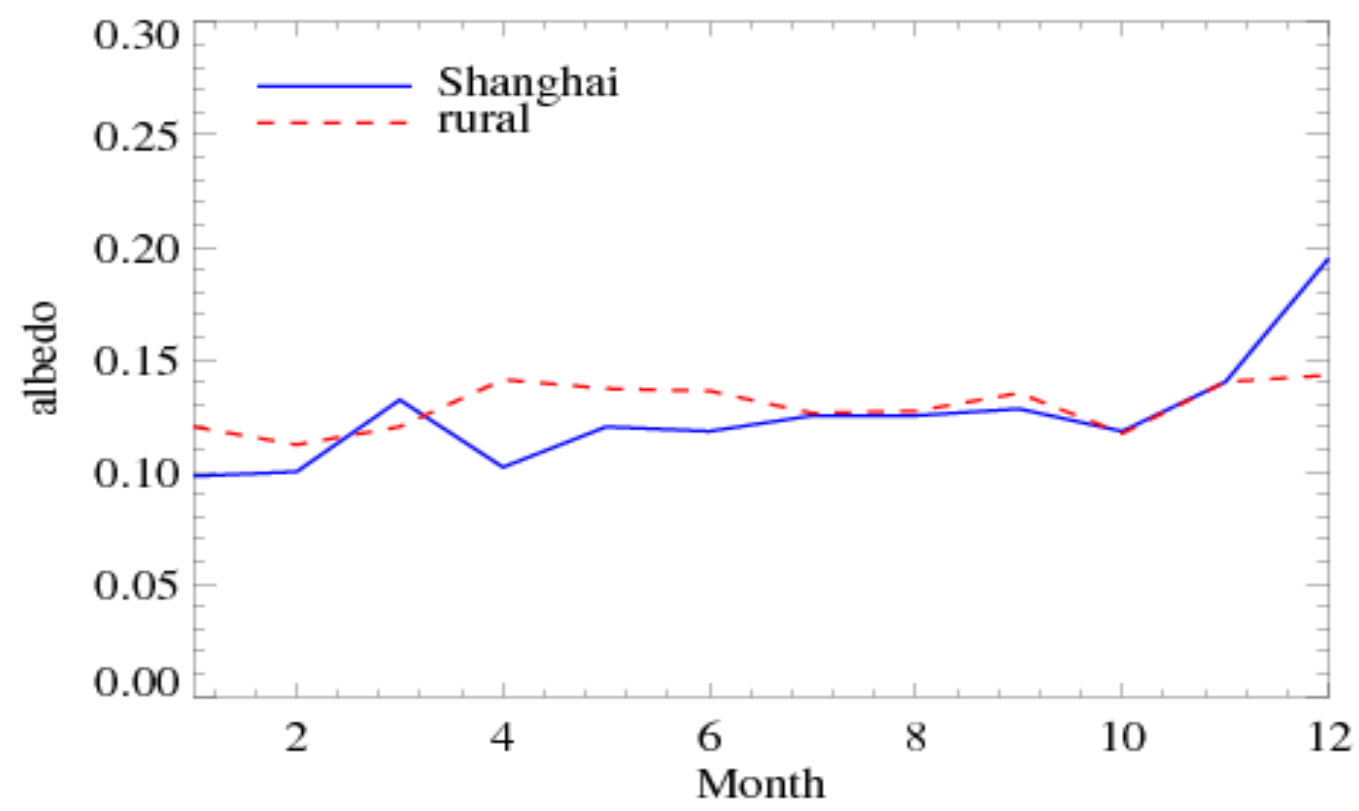

\section{Aerosol Optical Thickness (AOT)}

Aerosols in sky would reduce surface insolation via direct effect (Equation 1). Monthly aerosol optical thickness (AOT) from MODIS for Shanghai and the rural area are shown in Figure 8. Both maximum Shanghai and rural AOT are found in June with about 1.40 and 1.15 respectively, while Shanghai AOT has minimum in January and rural AOT minimum occurs in December. Minimum Shanghai and rural AOT occurring during winter may suggest that AOT is affected by temperature since certain chemical interactions may be function of air temperature. This is consistent with a previous study by Jin et al. [5], which also presented a minimum AOT was found in December during 2000-2003 for Houston and New York City. In general, Shanghai AOT is much larger than the rural AOT except for January, May, September, and November, since in those months Shanghai is slightly lower than rural regions. High AOTs are mainly due to large aerosol sources in urban, even though various studies suggested that urban and urban downwind regions have more rainfall [18] which may wash out aerosols.

The daily AOT observed from MODIS Terra 10:30 AM in July 2007 for both Shanghai and the rural regions (Figure 9) shows that most of instantaneous AOT for Shanghai are greater that the rural regions, which is consistent with results from the monthly AOT. Note that since MODIS aerosol retrieval limit, AOT can only be measured for clear days, and therefore, only a numbers of days in July has AOT observations. Nevertheless, such few observations clearly show its abrupt changes during a short period of time. For example, July 20, 2007 has high AOT by 1.8 and July 22, 2007, this value is dropped to 1, and by July 28, 2007, this value further drops to below 0.6. Such abrupt change of AOT is due to rainfall events which wash out the aerosol particles from the atmosphere. According to data 
from weather stations, it rains on 20 to 24 July, 2007 in Shanghai and then it rains again on July 28, 2007.

Figure 8. Monthly aerosol optical thickness (AOT) from MODIS in 2004, where the solid line represents Shanghai and the dashed line represents the rural regions.

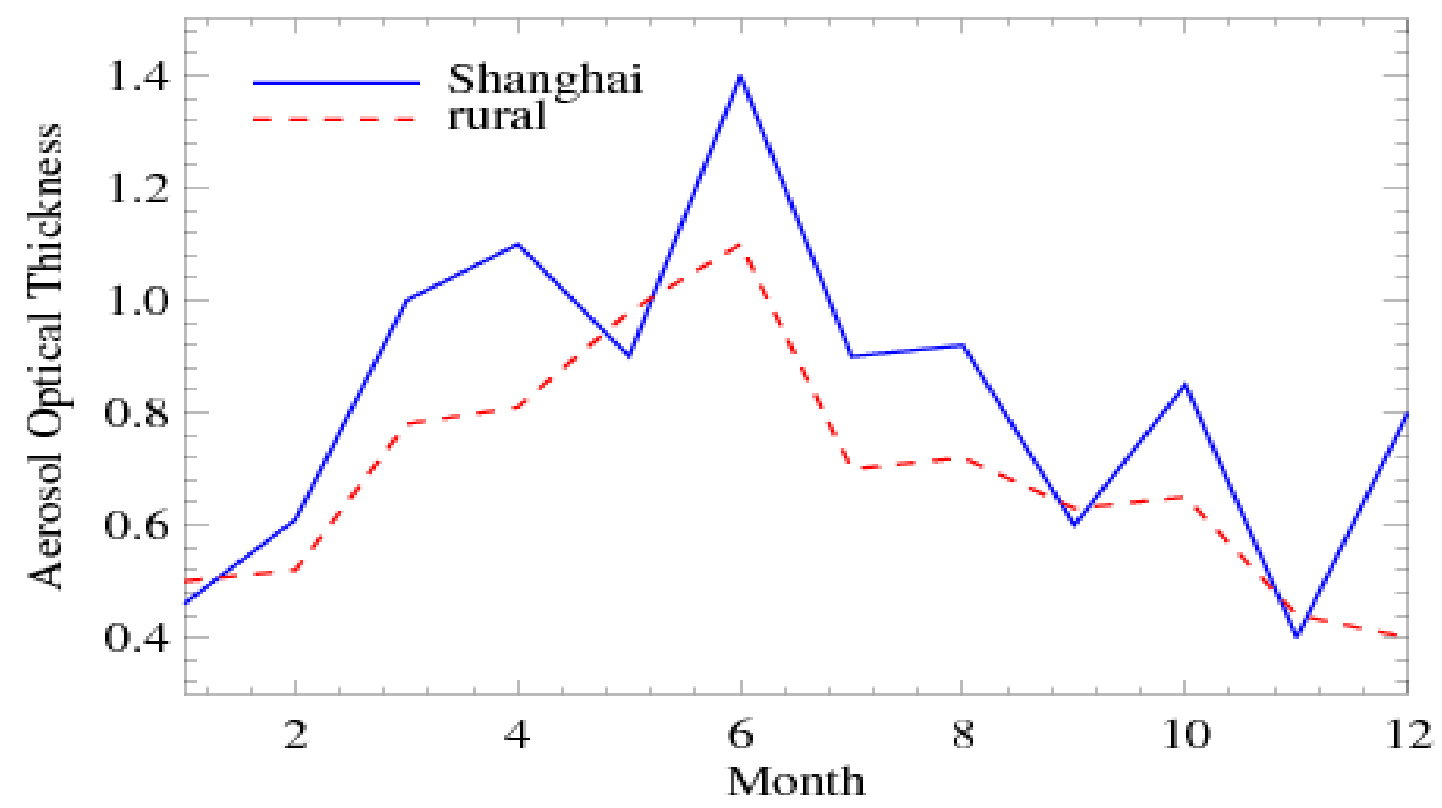

Figure 9. Daily MODIS observed aerosol optical thickness (AOT) for July 2007, where red solid line represents Shanghai and green solid line represents the rural regions.

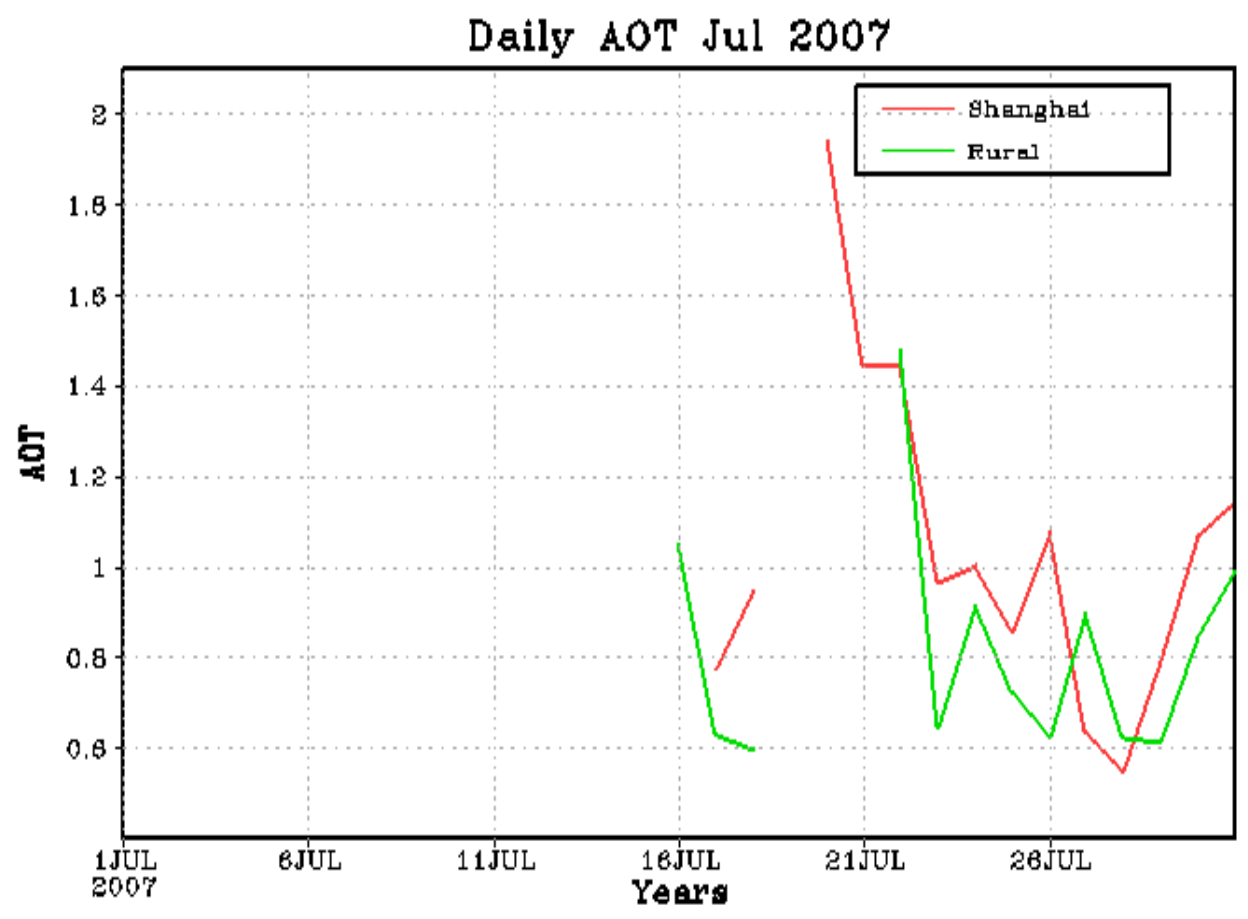

Due to the limits of MODIS AOT observations, ground instantaneous, continuous AOT observation is used to identify the diurnal, seasonal, and inter-annual variations. Aerosol Optical Thickness (AOT) 
at Taihu station from AERONET (Figures 10 and 11) is used in this study as an in situ data set along with AOT obtained from MODIS for Shanghai. A year-averaged, diurnal AOT appears to be higher during 10:00 AM-3:00 PM (Figure 10(a-d)), which may be related to the heavy traffic over nearby urban regions (Shanghai). Each year shows that diurnal AOT appear to increase after rush hours in the morning. In addition, AOT is expected to increase later in the night after rush hours in the evening but with no operation of sun photometer during the night, there are no measurements taken.

Figure 10. Diurnal AOT obtained from AERONET for Taihu in (a) 2005, (b) 2006, (c) 2007, and (d) 2008, where each black solid bar represents 95\% confidence interval $(1.96 \sigma)$.

(a)

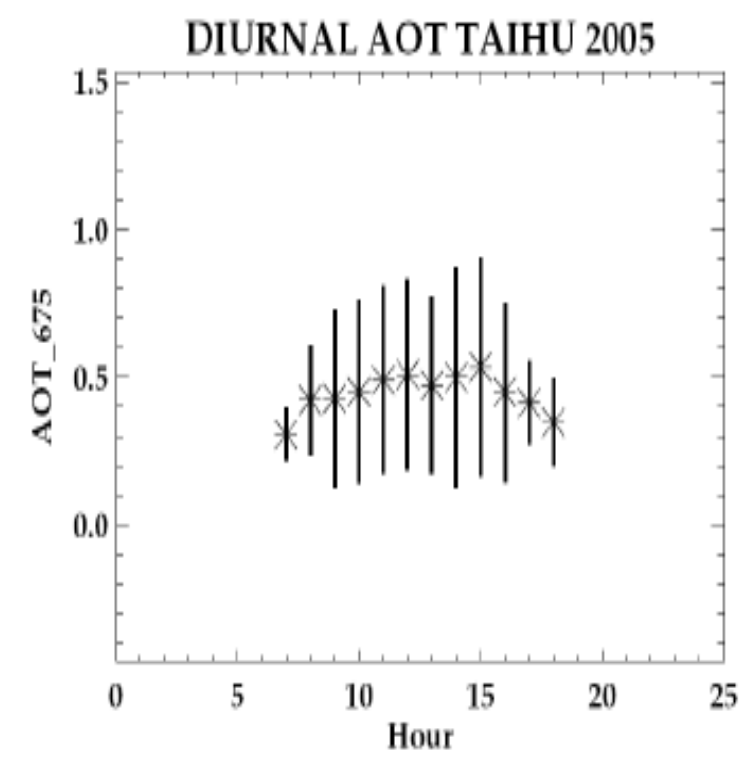

(c)

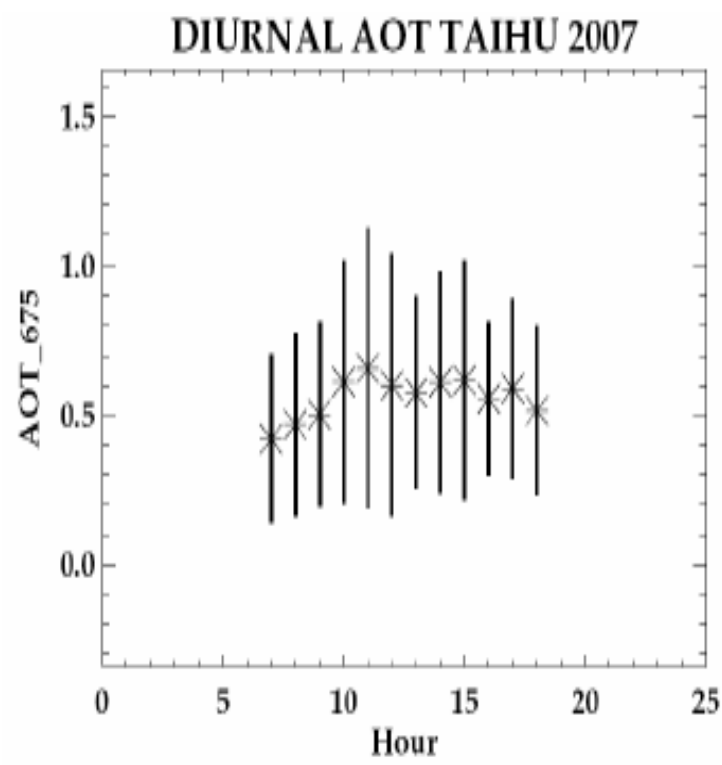

(b)

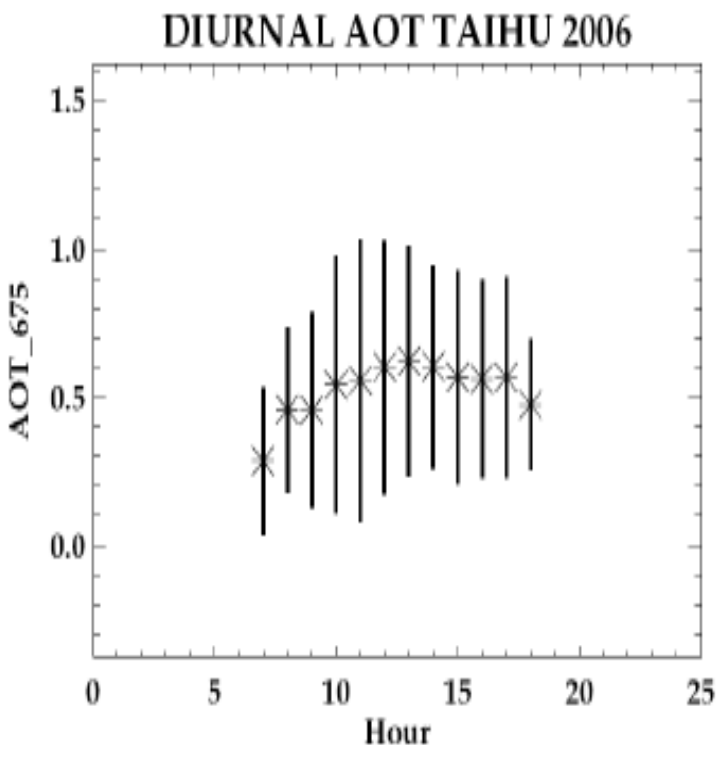

(d)

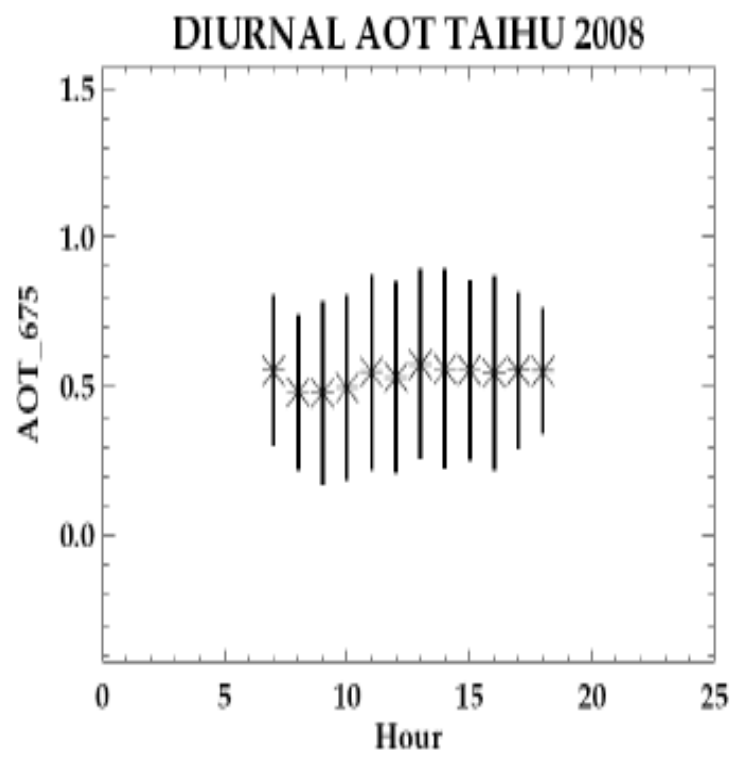

Month to month AOT variation of Taihu sampled from the instantaneous observations during 2005-2008 under the clear sky (Figure 11). Similar to the results obtained from MODIS, high AOT 
occurs in the summer time, specifically, June with about 0.85 in magnitude. The monthly AOT has gradually increased from January to June and then dropped to below 0.6 after June. The sharp reduction of AOT in July and August may be most related to the heavy rainfall season in Shanghai as a result of Asian Monsoon. Note that although monthly AOT from AERONET seems to have a similar trend as MODIS, magnitude of monthly AOT from AERONET in particular is much less than MODIS. This might be due to the uncertainty in MODIS land aerosol retrieval (King, personal communication 2009). In addition, large standard deviation $(\sigma)$ in July suggested the large AOT spread in this month because the standard deviation can indicate how much variations of one variable. The reason for such large variations in AOT needs to be studied in future.

Figure 11. Averaged monthly aerosol optical thickness (AOT) obtained from AERONET from 2005 to 2008, where black solid bar represents 95\% confidence interval (1.96б).

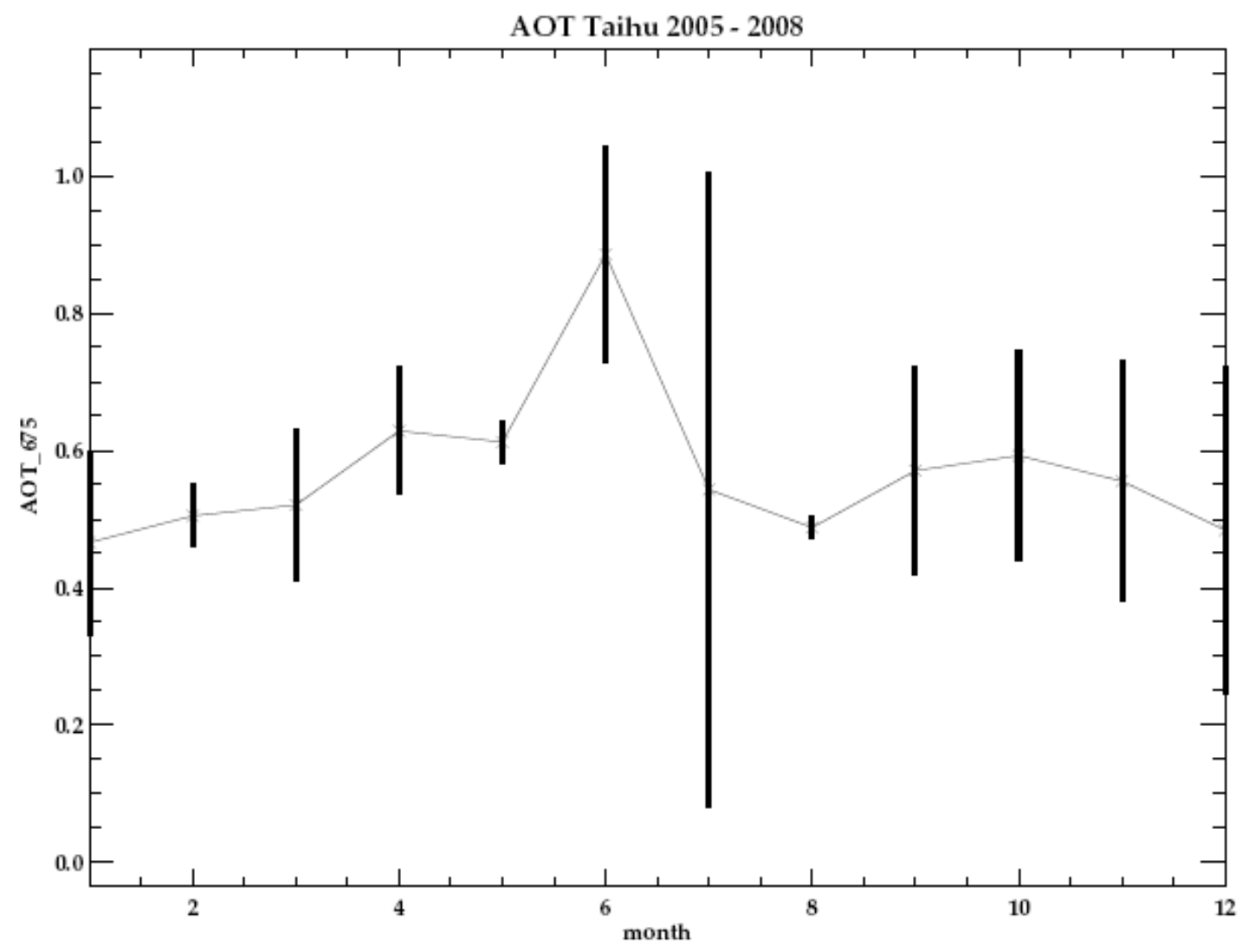

\section{Cloud Fraction and Water Vapor}

With more aerosols serving as cloud condensation nuclei and higher skin temperature leading to stronger convection over Shanghai, what would cloud formation change? The multi-year averaged cloud fraction (CF, Figure 12) for both Shanghai and the rural areas appear to be highly correlated, with the maximum CF in June and the minimum CF in February. Nevertheless, differences in CF are still evident for Shanghai and the rural regions due to the local mechanisms. The cloudiest period occurs in June as shown in Figure 12, which may be related to Asian monsoon system movement in this region. Later, CF drops sharply in July and August. The minimum CF is found in February where the amount of water vapor may be low during winter. Nevertheless, the large-scale dynamics seems to 
be the dominate factor for $\mathrm{CF}$ over such a relatively small region, and therefore there is high correlation in CF between Shanghai and the rural regions.

Figure 12. Multi-year averaged (2000-2008) cloud fraction for Shanghai and rural regions. Shanghai minus rural. Data is from monthly MODIS observations at 10:30 AM.

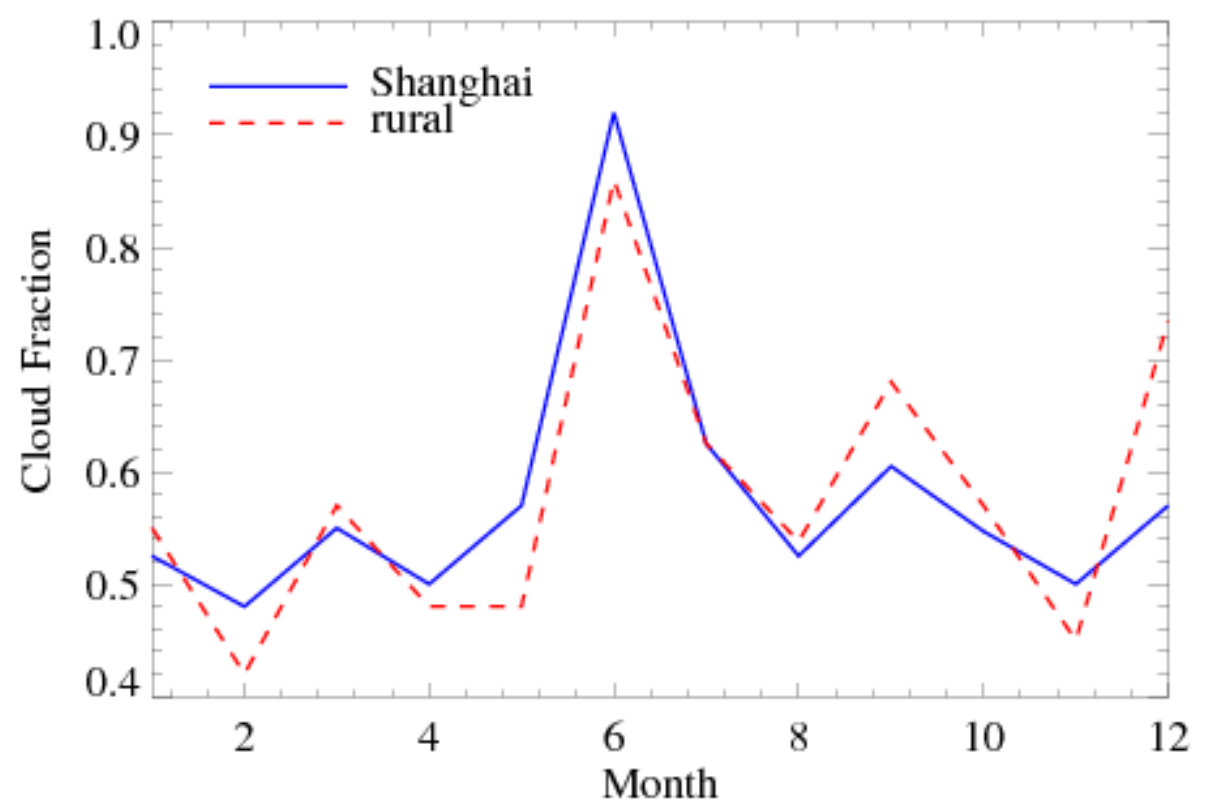

Competing mechanisms for water vapor supply exist for Shanghai and the selected rural region: On one hand, Shanghai locates on the coast of Pacific Ocean and thus has abundant water vapor supply. On the other hand, Shanghai does not have enough soil moisture for evaporation due to the large fraction of water-proof urban surface. As the rural area has more vegetations compared to Shanghai, the total amount of water vapor in rural is expected to be greater through evaporation. The multi-year averaged total column water vapor for Shanghai and the rural areas (Figure 13) shows that water vapor for both areas appear to be approximately the same for the most of the year except the differences in June, July, September, and November, with the largest difference $(-0.55 \mathrm{~cm})$ showing in July. Annual WV variations follow the surface temperature variation. Namely, WV increases as temperature increases from January through August, and then starts to gradually decrease as temperature decreases from August through December. Furthermore, during July and August, total amount of water vapor in the rural area are greater compared to Shanghai mainly due to evaporation through vegetation. Daily the amount of water vapor (Figure 14) in July 2007 show that daily water vapor in the rural area is greater compared to Shanghai. 
Figure 13. Muti-year averaged (2000-2008) water vapor for Shanghai and rural regions. Data is from monthly MODIS observations at 10:30 AM.

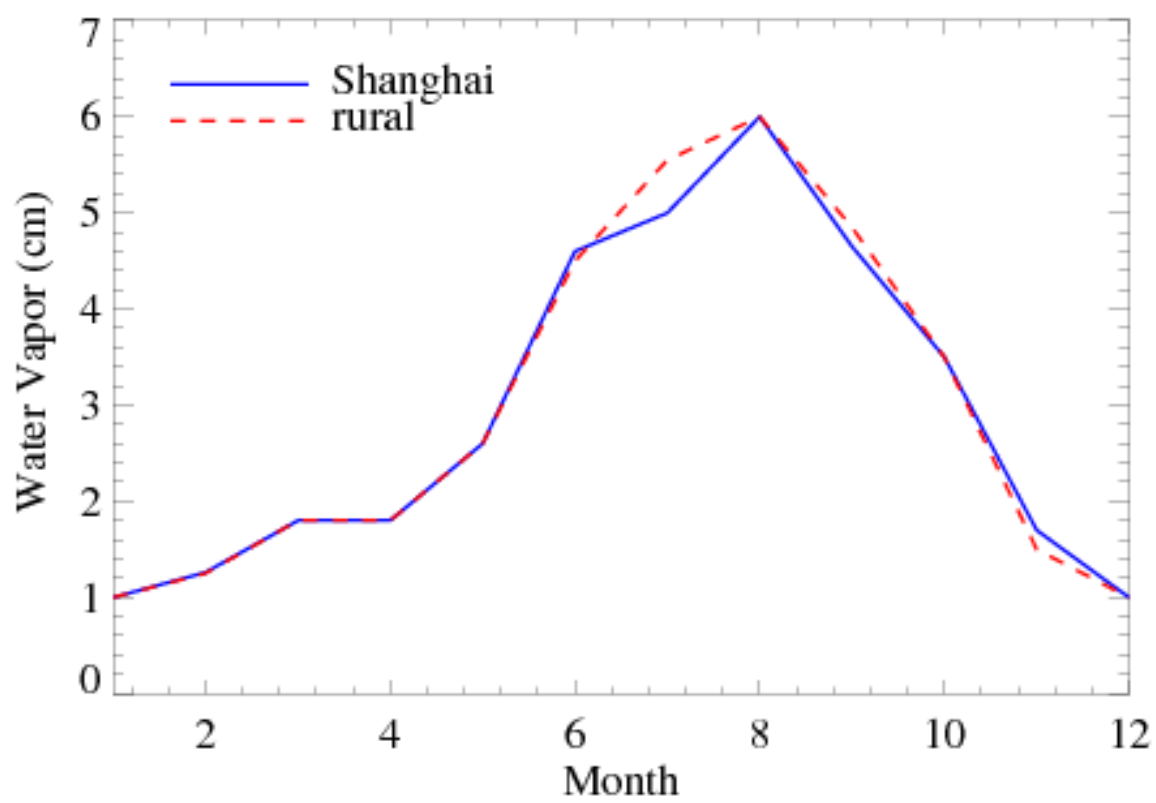

Figure 14. Daily water vapor for July 2007 for Shanghai and rural regions. Due to the cloudy days, only a few days have observations.

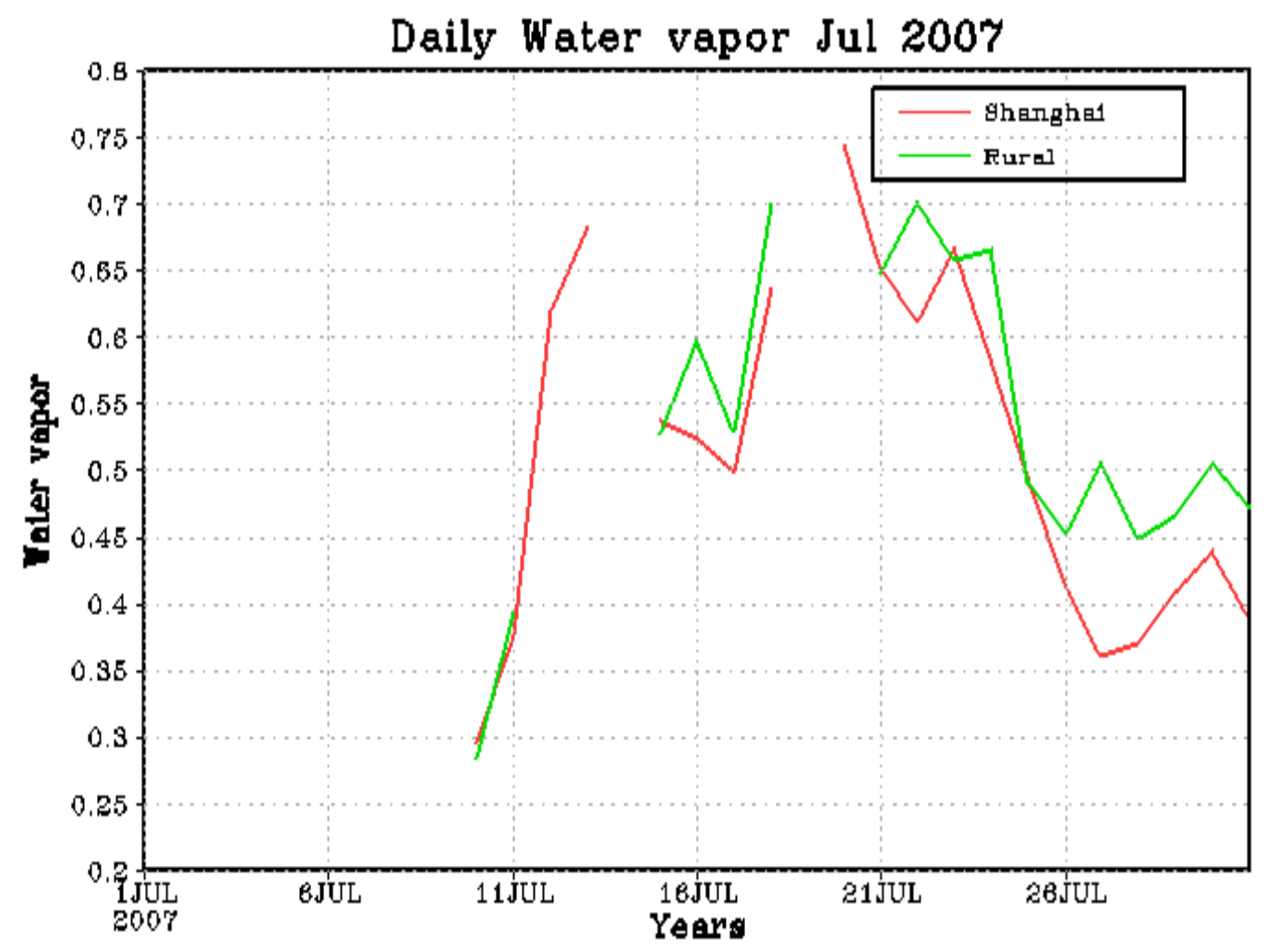




\section{Final Discussion-Land-Atmosphere Interactions}

Satellite observations, together with ground observations, reveal that urban is a unique climate system and is the extreme case of human-activity induced changes. By constructing buildings, parking lots, and roads, human being replace the natural vegetation-covered surface with water-proof concrete. Consequently, surface albedo (Figure 5) and surface emissivity (not shown, but see [8] Figure 9(b) and [19], Figure 5) are reduced. Meanwhile, vegetation cover is dramatically decreased in urban regions, and no soil moisture available from urban water-proof surfaces. All these directly contribute to the UHI phenomenon for urban system. As shown in Equation 1, reducing albedo leads to more solar radiation being kept at the urban surface instead of being reflected back to atmosphere; reducing surface emissivity leads to more thermal radiation kept at the surface instead of emitted into atmosphere; less soil moisture at the urban surface would reduce the Bowen ratio, namely, more energy is used to heat up the surface in terms of sensible heat flux instead of being redistributed into latent heat flux, and reduction in trees also reduce surface evapotranspiration. Simply put, the land surface physical properties and physical processes are dramatically changed by urbanization and result in UHI.

Why urban has low albedo? Here are some possible reasons: First, the dense building regions has canyon effect, which not only affects momentum and also results in the so-called "slope effect", namely, the building walls cause multiple reflection for solar photons, and therefore, eventually, fewer solar photons can be reflected back to atmosphere. This is part of the reason of urban low surface albedo. Another reason may be that the concrete material has low albedo than the natural surface in broadband albedo. Nevertheless, urban has high heterogeneity, and therefore urban surface abedo may not be uniformly lower than natural rural regions. This is because urban dry surface may also lead to a high surface albedo (wet surface is low albedo, an example for this is that wet sands look darker than dry sands).

Urbanization modifies atmosphere conditions, in terms of aerosol load, cloud, and water vapor. The land surface energy budget (Equation 1) can clearly disclose that the land-atmosphere interaction is very critical for an urban system. First, urban regions, especially for those big cities, distinguish with high urban aerosol load. Aerosols directly scatter or absorb solar radiation (aerosol direct effect) and thus reduce surface insolation [20]. This aerosol-reduce-surface insolation mechanism is a competing process for the land surface UHI processes and cools urban surface. Meanwhile, aerosols serve as cloud condensation nucli [7] and affect the microphysical properties of clouds (namely, aerosol's indirect effect). Jin and Shepherd [20] reported that over East Asia, more aerosols are related to smaller cloud droplet size for both water and ice clouds. In this study, the differences of cloud and water vapor between Shanghai and urban regions would suggest that urban has different clouds conditions, which is directly or indirectly related to urban aerosols.

\section{Acknowledgments}

This work was funded by NSF GEO/ATM/LARS/CLD grant (060928-9145) and by NASA PMM funding NNX07AF39G. 


\section{References}

1. Langsberg, H.E. Man-made climate change. Science 1970, 170, 1265-1274.

2. Oke, T.R. The energetic basis of the urban heat island. Quart. J. Roy. Meteor. Soc. 1982, 108, $1-24$.

3. Jin, M.; Shepherd, J.M. On including urban landscape in land surface model—How can satellite data help? Bull. Amer. Meteorol. Soc. 2005, 86, 681-689.

4. Dickinson, R.E.; Henderson-Sellers, A.; Kennedy, P.J.; Wilson, M.F. Biosphere-Atmosphere Transfer Scheme (BATS) for the NCAR Community Climate Model; NCAR Technical Note TN-275-STR; NCAR: Boulder, CO, USA, 1986; p. 48.

5. Jin, M.; Shepherd, J.M.; King, M.D. Urban aerosols and their interaction with clouds and rainfall: A case study for New York and Houston. J. Geophys. Res. 2005a, 110, D10S20, doi:10.1029/2004JD005081.

6. Kaufman, Y.J.; Tanré, D.; Remer, L.A.; Vermote, E.F.; Chu, A.; Holben, B.N. Operational remote sensing of tropospheric aerosol over land from EOS moderate resolution imaging spectroradiometer. J. Geophys. Res. 1997, 102, 17051-17067.

7. Twomey, C.J. The influence of pollution on the shortwave abedo of clouds. J. Atmos. Sci. 1979, 34, 1149-1152.

8. Jin, M.; Dickinson, R.E.; Zhang, D.-L. The footprint of urban areas on global climate as characterized by MODIS. J. Climate 2005a, 18, 1551-1565.

9. Wan, Z. New refinements and validation of the MODIS land-surafce temperature/emissivity products. Remote Sens. Environ. 2008, 112, 59-74.

10. Schaaf, C.B.; Gao, F.; Strahler, A.H.; Lucht, W.; Li, X.; Tsang, T.; Strugnell, N.C.; Zhang, X.; Jin, Y.; Muller, J.-P.; Lewis, P.; Barnsley, M.; Hobson, P.; Disney, M.; Roberts, G.; Dunderdale, M.; Doll, C.; d'Entremont, R.; Hu, B.; Liang, S.; Privette, J.L.; Roy, D.P. First operational BRDF, albedo and nadir reflectance products from MODIS. Rem. Sens. Environ. 2002, 83, 135-148.

11. Gao, F.; Schaaf, C.; Strahler, A.; Roesch, A.; Lucht, W.; Dickinson, R. The MODIS BRDF/Albedo Climate Modeling Grid Products and the variability of albedo for major global vegetation types. J. Geophys. Res. 2005, 110, D01104, doi:10.1029/2004JD00519.

12. Friedl, M.A.; McIver, D.K.; Hodges, J.C.F.; Zhang, X.Y.; Muchoney, D.; Strahler, A.H; Woodcock, C.E.; Gopal, S.; Schneider, A.; Cooper, A.; Baccini, A.; Gao, F.; Schaaf, C. Global land cover mapping from MODIS: Algorithms and early results. Remote Sens. Environ. 2002, 83, 287-302.

13. King, M.D.; Menzel, W.P.; Kaufman, Y.J.; Tanré, D.; Gao, B.C.; Platnick, S.; Ackerman, S.A.; Remer, L.A.; Pincus, R.; Hubanks, P.A. Cloud and aerosol properties, precipitable water, and profiles of temperature and humidity from MODIS. IEEE Trans. Geosci. Remote Sens. 2003, 41, 442-458.

14. Gao, B.-C.; Yang, P.; Guo, G.; Park, S.K.; Wiscombe, W.J.; Chen, B. Measurements of water vapor and high clouds over the Tibetan Plateau with the Terra MODIS instrument. IEEE Trans. Geosci. Remote Sens. Lett. 2003, 41, 895-900. 
15. Platnick, S.; King, M.D.; Ackerman, S.A.; Menzel, W.P.; Baum, B.A.; Riédi, J.C.; Frey, R.A. The MODIS cloud products: Algorithms and examples from Terra. IEEE Trans. Geosci. Remote Sens. Lett. 2003, 41, 459-473.

16. Holben, B.N.; Eck, T.F.; Slutsker, I.; Tanré, D.; Buis, J.P.; Setzer, A.; Vermote, E.; Reagan, J.A.; Kaufman, Y.J.; Nakajima, T.; et al. AERONET-A federated instrument network and data archive for aerosol characterization. Remote Sens. Environ. 1998, 66, 1-16.

17. O’Neill, N.T.; Eck, T.F.; Smirnov, A.; Holben, B.N.; Thulasiraman, S. Spectral discrimination of coarse and fine mode optical depth. J. Geophys. Res. 2005, 108, 4559-4573.

18. Shepherd, J.M.; Pierce, H.; Negri, A.J. Rainfall modification by major urban areas: Observations from spaceborne rain radar on the TRMM satellite. J. Appl. Meteorol. 2002, 41, 689-701.

19. Jin, M.; Liang, S. Improving land surface emissivity parameter of land surface model in GCM. J. Climate 2006, 19, 2867-2881.

20. Jin, M.; Shepherd, J.M. Aerosol relationships to warm season clouds and rainfall at monthly scales over east China: Urban land versus ocean. J. Geophys. Res. 2008, 113, D24S90, doi:10.1029/2008JD010276.

(C) 2011 by the authors; licensee MDPI, Basel, Switzerland. This article is an open access article distributed under the terms and conditions of the Creative Commons Attribution license (http://creativecommons.org/licenses/by/3.0/). 